\title{
Welcoming Philippe Coussot as the next European editor
}

\author{
Lynn M. Walker ${ }^{1}$ \\ Received: 7 April 2021 / Accepted: 8 April 2021 / Published online: 20 April 2021 \\ (c) The Author(s), under exclusive licence to Springer-Verlag GmbH Germany, part of Springer Nature 2021
}

Keywords Editor $\cdot$ European $\cdot$ Coussot

When Rheologica Acta became the Official Journal of the European Society of Rheology (ESR) in 2006, the journal added a second editor to share responsibilities and better serve the rheological community. The first European editor was Dimitris Vlassopoulos (2006-2011), followed by Jan Vermant (2011-2021), who have both increased the visibility and breadth of the journal over the past 15 years. This year, the editorial team of Rheologica Acta welcomes our next European editor, Philippe Coussot. We take this opportunity to thank Jan Vermant for his tireless work towards the journal over the last decade.

Philippe has been contributing to the quality and depth of Rheologica Acta for more than 25 years. His first contribution on the flow behavior of fine mud suspensions (Coussot and Piau 1994) set the stage and has been followed by a continuous stream of contributions on practical and fundamental problems in flow of complex fluids (Coussot and Boyer 1995; Tabuteau et al. 2004, 2007; Ragouilliaux et al. 2006; Ovarlez et al. 2009; Boujlel and Coussot 2012; Fourmentin et al. 2015; Coussot 2018; Andrade and Coussot 2020). Philippe has contributed to the journal in other important ways; he has provided context to special issues from proceedings of conferences and symposia (Coussot and Wagner 2009; Tassin et al. 2010) and recently guest edited and contributed to the issue Yield Stress Fluids: 100 Years after Bingham's Landmark Paper (Vol 56, Issue 3) (Coussot 2017; Coussot et al. 2017). This issue is proving to be a reference collection of work for those working with yielding materials.

Philippe has been extensively involved in the European Society of Rheology, including being recognized with the 2017 Weissenberg Award for his outstanding, long-term achievements within the field of rheology. Philippe will maintain the strong connection to the journal and continue to find ways for the journal to serve the community.

The submission of papers to Rheologica Acta is not affected. The two editors, Lynn M. Walker and Philippe Coussot, will alternate in taking responsibility in guiding your manuscript through the review process. Please continue to submit your papers through the Springer Nature website.

Philippe Coussot joins the Editorial Team of Rheologica Acta
Lynn M. Walker

lwalker@andrew.cmu.edu

1 Department of Chemical Engineering, Carnegie Mellon University, Pittsburgh, PA 15213, USA

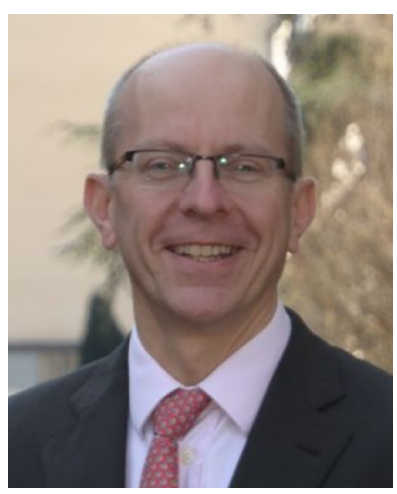




\section{References}

DE Andrade V, Coussot P (2020) Thermal fatigue and collapse of waxy suspensions. Rheol ACTA 59:279-289. https://doi.org/10.1007/ s00397-020-01202-y

Boujlel J, Coussot P (2012) Measuring yield stress: a new, practi$\mathrm{cal}$, and precise technique derived from detailed penetrometry analysis. Rheol ACTA 51:867-882. https://doi.org/10.1007/ s00397-012-0643-9

Coussot P (2017) Bingham's heritage Rheol ACTA 56:163-176. https://doi.org/10.1007/s00397-016-0983-y

Coussot P (2018) Slow flows of yield stress fluids: yielding liquids or flowing solids? Rheol ACTA 57:1-14. https://doi.org/10.1007/ s00397-017-1055-7

Coussot P, Boyer S (1995) Determination of yield stress fluid behaviour from inclined plane test. Rheol ACTA 34:534-543. https://doi. org/10.1007/BF00712314

Coussot P, Malkin AY, Ovarlez G (2017) yield stress-or 100 years of rheology Introduction. Rheol ACTA 56:161-162. https://doi.org/ 10.1007/s00397-017-1003-6

Coussot P, Piau JM (1994) On the behavior of fine mud suspensions. Rheol Acta 33:175-184. https://doi.org/10.1007/BF00437302

Coussot P, Wagner NJ (2009) The future of suspension rheophysics: comments on the 2008 workshop. Rheol ACTA 48:827-829. https://doi.org/10.1007/s00397-009-0380-x
Fourmentin M, Ovarlez G, Faure P et al (2015) Rheology of lime paste-a comparison with cement paste. Rheol ACTA 54:647-656. https://doi.org/10.1007/s00397-015-0858-7

Ovarlez G, Rodts S, Chateau X, Coussot P (2009) Phenomenology and physical origin of shear localization and shear banding in complex fluids. Rheol ACTA 48:831-844. https://doi.org/10.1007/ s00397-008-0344-6

Ragouilliaux A, Herzhaft B, Bertrand F, Coussot P (2006) Flow instability and shear localization in a drilling mud. Rheol ACTA 46:261-271. https://doi.org/10.1007/s00397-006-0114-2

Tabuteau H, Baudez JC, Bertrand F, Coussot P (2004) Mechanical characteristics and origin of wall slip in pasty biosolids. Rheol ACTA 43:168-174. https://doi.org/10.1007/s00397-003-0331-x

Tabuteau H, Baudez JC, Chateau X, Coussot P (2007) Flow of a yield stress fluid over a rotating surface. Rheol ACTA 46:341-355. https://doi.org/10.1007/s00397-006-0125-z

Tassin JF, El Kissi N, Coussot P (2010) Foreword: special issue on papers presented at the de Gennes Discussion Conference, Chamonix, February 1st-5th, 2009. Rheol ACTA 49:423-424. https:// doi.org/10.1007/s00397-010-0451-Z 